\title{
STRUCTURAL FACTORS FOR A THIRD-GENERATION PORT: PLANNING INTERVENTIONS FOR MECHANICAL LOGISTICS IN GIOIA TAURO, ITALY
}

\author{
GIUSEPPE MUSOLINO ${ }^{1}$, ANTONIO CARTISANO ${ }^{2} \&$ GIUSEPPE FORTUGNO $^{2}$ \\ ${ }^{1}$ Dipartimento di Ingegneria dell'Informazione, delle Infrastrutture e dell'Energia Sostenibile, \\ Università Mediterranea di Reggio Calabria, Italy \\ ${ }^{2}$ Professional Engineer, Transportation Specialist, Italy
}

\begin{abstract}
Third-generation ports are a strategic asset for the economic development of a territory. They represent an infrastructure that goes beyond the services related to the loading/unloading of goods and that offers the complete cycle of services within the supply chain. The port of Gioia Tauro is the first transhipment container (lift-on/lift-off) port and one of the most important for the (roll-on/roll-off) international traffic of road vehicles (automotive) of Italy. The increasing number of handled containers in 2020 is not enough to achieve the goal of making the port of Gioia Tauro one of the first European ports of the Southern Range. It's necessary to fully develop its "third-generation" nature. This condition would allow to attract new companied, to increase the local production, the import and the export of the Calabrian regional economy. One of the possible ways to achieve this goal is the development of the logistics connected to the mechanical sector, with a specific focus on automotive. This sector in Calabria quotes about one third on the value of regional exports. The characteristics of the production plants is similar to that of the rest of the Italy: small and medium-sized enterprises are flanked by some settlements of world-leading multinational groups. The paper focuses on the logistics for the mechanical sector in Calabria, analysing the current criticalities and defining the development scenarios and the planned interventions strategies to be undertaken in the port of Gioia Tauro.
\end{abstract}

Keywords: third-generation ports, mechanical sector, logistics, Gioia Tauro port.

\section{INTRODUCTION}

Ports are crucial nodes in the international transport system and play an important role in the economy of countries, but also in the local economy of territory where they are located.

UNCTAD introduced the concept of port generation to classify commercial ports (see [1]-[3]). This concept makes it possible to identify the core characteristics of a port by assigning it to one generation or another.

For centuries port continued to carry out their millenary function of landing from the sea, of temporary storage and transfer of goods. Ports were traditionally built-in proximity to the cities and they acted as the gate for the urban economy in the exchange of freight with other cities. They are called first generation of ports.

During the XX century industrial and commercial activities were added to the original functions of the ports. New ports were built together with great industrial areas, offering industrial or commercial services to industrial plants. They are called second generation of ports.

After 1980, ports evolved in order to adapt themselves to the revolution introduced by containerization and to the new requirements of international trade. Ports became integrated transport centres and logistic platforms. They increased their added value of the goods that transit through them, due to the manipulations of the goods themselves. This class of ports is the third-generation of ports.

Starting from 2000, the development strategy of ports was the creation of port communities and the strengthening of the network that put in relation physically separate 
ports, or terminals, through common operators or administrations. This transformation had its core in the integration of logistics. Ports became a hub where economic operations and activities, belonging to different ports, took place on an international scale. Port moved towards fourth generation.

The objective of the paper is to identify the scenarios and the interventions on mechanical logistics in order to let port of Gioia Tauro fully become a third-generation port, with a specific focus on automotive. This implies that, while consolidating the core business of transhipment, the settlement and consolidation of mechanical manufacturing, which is one of the pillars of the regional economy, should be stimulated in Gioia Tauro.

The scenarios and the interventions concerning the mechanical logistics are defined inside the Regional Transport Plan of Calabria (see [4]-[6]), and inside the strategic report of the Integrated Logistics Area [7], identified after the Partnership Agreement 2014-2020 between Italy and the European Commission.

The aim of the planned scenarios and interventions is to boost the development of the port hinterland. Among the others, a cluster of interventions was defined in order to enhance the development of mechanical logistics to facilitate the growth of the regional mechanical sector.

The remaining part of the paper is articulated as follows. Section 2 presents the conceptual elements of the methodology adopted in the paper. Section 3 presents the current situation and the critical elements in Calabria (Italy), as far as concerns the mechanical sector and logistics. Sections 4 reports the scenarios in the mechanical logistics and the planned interventions in the port of Gioia Tauro. Finally, the last section reports the conclusions and the perspectives.

\section{METHODOLOGY}

Nowadays global firms operating in the mechanical sector (e.g. automotive), whose intermediate and final productions are generally distributed among several plants, look for a third-generation port as a generator of value added, rather than a centre of cost. This could happen when the port is equipped with:

- material infrastructures, such as logistics and storage areas, intermodal centres, last-mile connections with railway and road networks;

- immaterial infrastructures; concerning tax incentive tools, research and training centres, ICT (Information Communication Technology).

The above dotation of infrastructures ensures the third-generation port to be embedded inside the maritime trade network and inside the global supply-chain.

There are several methods and models in literature able to clarify the link between the definition of "third generation" port and the integration of logistics related to a single industrial sector (such as the mechanical one). In general, they allow to estimate:

- the link between the economy (production, consumption, trade) and the supply chain, providing the quantity of freight generated in production areas and the quantity of freight distributed among intermediate and final consumption areas, in relation to the dotation of transport and logistics infrastructures;

- the economic impacts (e.g. value added, employment) generated by existing transport and logistic operations (e.g. freight handled and manipulated) inside the port area and the port hinterland, where the port is considered as a node of the supply chain.

The existing methods and models are classified into two main categories [8], according to the level of representation of the economy: disaggregated vs. aggregated. 
The most common class of disaggregated models rely on the Multi-Regional-InputOutput (MRIO) approach (see [9]-[12]). MRIO model offers the advantage to estimate sector multipliers and to include within these multipliers both the indirect and the induced effects, through the identification of inter-sectoral linkages. On the other hand, MRIO models need extended surveys about the structure of the economy to be calibrated. Recent evolutions of MRIO models provide an assessment of the port embeddedness inside the maritime trade network and inside the global supply-chains. They establish the link between ports and the maritime trade flows, on one side, and between ports and the local economy of the port hinterland, on the other side [13].

Aggregated approaches provide general estimates concerning economic variables (such as value added, employment) for a single industrial sector, neglecting the inter-sectorial linkages as in the case of MRIO. In many cases, the economic variables referred to a port are estimated by specifying and calibrating a linear multiplier (e.g. assuming the existing and potential freight handling and storage capacity, as independent variables).

The paper presents an aggregate approach to define the development directions and the planned interventions to boost the mechanical sector in the port of Gioia Tauro, articulated into the following steps (see also [4]-[7]):

- identification of the current characteristics of the mechanical sector in Calabria and of critical elements of mechanical logistics (Section 3.1);

- current and potential import/export propensity of the mechanical sector, in order to determine the reference market of the port (Section 3.2);

- identification of the strategic development directions and of planned transport interventions (Sections 4.1 and 4.2), and estimation of the future logistic capacity of the port to support mechanical sector (conclusions).

\section{CURRENT SITUATION IN CALABRIA (ITALY)}

\subsection{Mechanical sector and logistics}

The mechanical sector is fundamental for the positioning of Italy at the top of the world-wide industrial production. The sector employed about 1,650,000 people in 2014 (Germany among European countries has more employees in the sector), producing about 100 billion euros of added value ( $7 \%$ of the economy and $40 \%$ of industry strictly speaking) and 191 billion of export (about $50 \%$ of value added) [14].

The importance of the sector is also established in strategic terms, as it transmits innovation to the rest of the industrial and economic sectors, supporting their competitiveness. From year 2008, the global crisis has changed the mechanical sector in Italy, which has known a dramatic drop in the domestic market, while foreign markets returned to pre-crisis levels. Both medium-large and small companies reacted to this situation, by concentrating on foreign markets and by searching for new outlet markets. The characteristics of Italian mechanical sector, based more on product quality and on production flexibility rather than on price, can make difficult to turn towards new markets, as this strategy requires investments in research and development that small companies cannot afford [15].

In this context, large companies play an important role, acting as leader and driver in research and development for the smaller companies belonging to the supply chain. In order to reach more complex and higher value-added markets, it should be necessary to develop the whole supply chain from leading companies to smaller ones. While large companies have the strength to search for new international markets, small companies should increase the 
added value of their products by means of more efficient production practices, innovations in process and product [15].

The mechanical sector in Calabria does not have high specialization indices in terms of number of companies and employees, if compared to the rest of Italy. However, it is important in the regional economy, especially if evaluated in relation to three characteristics: capital intensity, highly qualified workforce, strong presence of engineers and high-level technical personnel [16].

The sector weights about one third on the value of regional exports. It has local production units of world-leading multinational groups and presents interactions with universities and research centres of the area, but yet not fully structured.

The structure of mechanical production in Calabria is similar to the rest of Italy: some settlements of large leading companies are flanked by small and medium-sized manufacturing units. The sector's specializations, both in terms of number of firms and of employees, are that of metal products manufacturing, in particular of large metal carpentry (Table 1).

Table 1: Employees number and active companies in Italy, South of Italy and Calabria (2011) [17].

\begin{tabular}{|l|c|c|c|c|c|c|}
\cline { 2 - 7 } \multicolumn{1}{c|}{} & \multicolumn{2}{c|}{ Italy } & \multicolumn{2}{c|}{ South } & \multicolumn{2}{c|}{ Calabria } \\
\cline { 2 - 7 } \multicolumn{1}{c|}{} & Employees & Companies & Employees & Companies & Employees & Companies \\
\hline Metallurgy & 126,451 & 3,908 & 5,834 & 612 & 351 & 92 \\
\hline $\begin{array}{l}\text { Metal products } \\
\text { (excluding machines } \\
\text { repair and } \\
\text { maintenance) }\end{array}$ & 544,225 & 71,551 & 62,610 & 12,124 & 5,750 & 1,579 \\
\hline $\begin{array}{l}\text { Computers, } \\
\text { electronic products, } \\
\text { optics, measurement } \\
\text { and watches }\end{array}$ & 112,055 & 5,693 & 6,474 & 508 & 208 & 46 \\
\hline $\begin{array}{l}\text { Electrical equipment } \\
\text { and non-electrical } \\
\text { household use }\end{array}$ & 166,095 & 9,104 & 6,460 & 809 & 350 & 80 \\
\hline $\begin{array}{l}\text { Machineries and } \\
\text { equipment }\end{array}$ & 457,956 & 24,584 & 16,566 & 1,768 & 893 & 136 \\
\hline $\begin{array}{l}\text { Vehicles, trailers and } \\
\text { semi-trailers }\end{array}$ & 168,034 & 2,402 & 26,426 & 326 & 77 & 24 \\
\hline $\begin{array}{l}\text { Other transport } \\
\text { means }\end{array}$ & 85,483 & 2,773 & 10,396 & 366 & 194 & 31 \\
\hline $\begin{array}{l}\text { Repair, maintenance } \\
\text { and installation of } \\
\text { machines }\end{array}$ & 160,179 & 38,666 & 24,043 & 5,713 & 2,212 & 601 \\
\hline $\begin{array}{l}\text { Total mechanical } \\
\text { companies }\end{array}$ & $1,820,478$ & 158,681 & 158,809 & 22,226 & 10,035 & 2,589 \\
\hline $\begin{array}{l}\text { Total active } \\
\text { companies }\end{array}$ & $16,424,086$ & $4,425,950$ & $2,373,852$ & 857,270 & 274,896 & 109,987 \\
\hline $\begin{array}{l}\text { Mechanical } \\
\text { companies/active } \\
\text { companies }\end{array}$ & $11.1 \%$ & $3.6 \%$ & $6.7 \%$ & $2.6 \%$ & $3.7 \%$ & $2.4 \%$ \\
\hline
\end{tabular}


The main mechanical poles present in Calabria, where the leading firm belongs to a multinational leading company, are centred around of Nuovo Pignone in Vibo Valentia, and around of Hitachi Rail (ex-Ansaldo Breda) in Reggio Calabria [18].

Nuovo Pignone, active since 1962, is specialized in the construction of mechanical systems for the oil and gas industry. The plant, initially belonged to the ENI Group and was acquired by American General Electric in the 1990s, needs 400 employees at full capacity, but it is of about 100 employees today. Nevertheless, the induced activities generated by Nuovo Pignone in the closer industrial area has about a thousand employees.

Hitachi Rail (ex-Ansaldo Breda) plant is settled in Reggio Calabria, and it is specialized in the construction of trains. The direct employment is of about 500 employees and also in this case, there are a number of firms and employees involved in induced activities.

There are other plants settled in the region, some of them are recalled below.

CADIS, a company that produces aluminium products for the European and North African markets, and FB Engineering, specialized in the construction of rotation turbochargers, have a production plant in Cosenza. Ital Tractor Sud, a manufacturer of earthmoving machinery, has a factory in Catanzaro, while Metal Carpenteria, part of Industrie Meccaniche Cremonesi, is located in Crotone.

There is also a relevant number of medium and small mechanical firms. One of the most dynamic ones is De Masi Industrie Meccaniche, which operates in Gioia Tauro (RC) in the construction and trade of agricultural machinery. The firm invests massively in research and development to create and develop high-tech devices and products.

The critical elements of the mechanical sector are reported in the following. In recent years the freight transport and logistics have undergone a phase of profound restructuring to respond to changes in global trade and in the new forms of production. The companies do not limit themselves to optimizing the internal production process and the transport; but they decide where to locate the intermediate and final productions. The territories respond to this new demand for transport and logistics, in a competition that is global, offering: material infrastructures, such as ports, logistics areas, intermodal centres; immaterial infrastructures; concerning research, training and ICT (Information Communication Technology).

The productions, in particular the final ones, are located close to interchange points (ports, logistic areas), able to satisfy the demand of companies both in terms of material and immaterial infrastructures, and services.

The presence of the companies described above, located in Calabria, and the deployment of other measures by the Regional Government of Calabria, such as the Special Economic Zone (SEZ) of Gioia Tauro (see [19], [20]), makes it necessary to identify strategic scenarios and a cluster of interventions to facilitate the development of mechanical logistics in the port of Gioia Tauro. This is necessary in order to allow the growth of mechanical sector and, in general, a driving sector in the economy of Calabria.

\subsection{Export of the mechanical sector}

The export propensity, defined as the ratio between export and GDP, of firms from Calabria is much lower than the Italian average (1\% vs. $27 \%)$. Within a rather closed context to international trade, the mechanical sector has a relevant weight, equal to about $30 \%$ of total regional exports, and it rises to $60 \%$ in some areas.

The export firms decreased in years 2013-2015 (see Table 2), remaining however the second sector after the agri-food one. This reduction is due to the decline in the provinces of Catanzaro and Vibo Valentia. Reggio Calabria recorded an expansion of mechanical exports, showing a vitality of the regional mechanical sector. 
Table 2: Export from Calabria (Euro). Years 2013, 2014, 2015 [16].

\begin{tabular}{|l|c|c|c|}
\cline { 2 - 4 } \multicolumn{1}{c|}{} & \multicolumn{3}{c|}{ Export (Euro) } \\
\cline { 2 - 4 } \multicolumn{1}{c|}{ Sub-sectors } & 2013 & 2014 & 2015 \\
\hline Basic metals and metal products, & $57,563,150$ & $28,875,332$ & $31,382,357$ \\
except machines and plants & & & \\
Computers, electronic and optical & $2,737,168$ & $2,346,422$ & $2,746,864$ \\
devices & $3,450,250$ & $2,814,422$ & $2,586,875$ \\
Electronic devices & $35,347,993$ & $31,238,516$ & $34,341,406$ \\
machineries and devices & $9,297,734$ & $7,610,328$ & $6,169,648$ \\
Transport vehicles & $108,396,295$ & $72,884,874$ & $77,227,150$ \\
\hline Total mechanical export & $263,786,908$ & $234,038,541$ & $263,299,155$ \\
\hline Total Calabria export & \multicolumn{3}{c}{} \\
\hline
\end{tabular}

A relevant activity, with high potential development, is related to the logistics supporting the automotive sector and providing the supply to final industrial processes. Since 2003 Automar has been managing a terminal in the port of Gioia Tauro, which is a hub for imports - exports of cars in the Mediterranean and intercontinental markets. The terminal, with an area of 320,000 square meters and a storage capacity of 15,000 cars, is equipped to manage integrated logistics services for cars and commercial vehicles via roll-on/-roll-off maritime services, road and railways services. Automar has a technical centre provides services including inspection, optional installation, repair and painting.

\section{GIOIA TAURO: FULL THIRD-GENERATION PORT}

This section illustrates the port of Gioia Tauro as test case, where some scenarios and interventions are proposed in order to complete the status of third-generation port, according to the classification proposed by UNCTAD (see [1], [2]) and by further publications [3]. The scenarios and interventions concerning general logistics, hinterland regeneration and smart town, research and development, agri-food, are detailed presented respectively in [21]-[24].

The scenario and interventions concerning the mechanical aim to intersect with the trajectories, presented in the previous section, of the mechanical companies located in Calabria, where international groups settled with an individual plant are connected with smaller local firms belonging to the supply chain.

\subsection{Strategic development directions}

The port of Gioia Tauro (Fig. 1) is the first container transhipment port and one of the most important port for the automotive logistics of Italy [7]. The container traffic was 2.55 million of TEUs and the number of handled vehicles was 213,000 in year 2019; while in 2020 the port of Gioia Tauro was one of the few ports, that increased the container traffic: $+26 \%$ respect to 2019. In general, the container transport market of the Euro-Mediterranean region is increasing, even if there is a strong competition between the Mediterranean ports. Some estimates, indicate for 2025 a number of containers handled between 78 (instability case) and 84 million TEU (recovery case) in the Mediterranean basin (see [25]-[27]). 


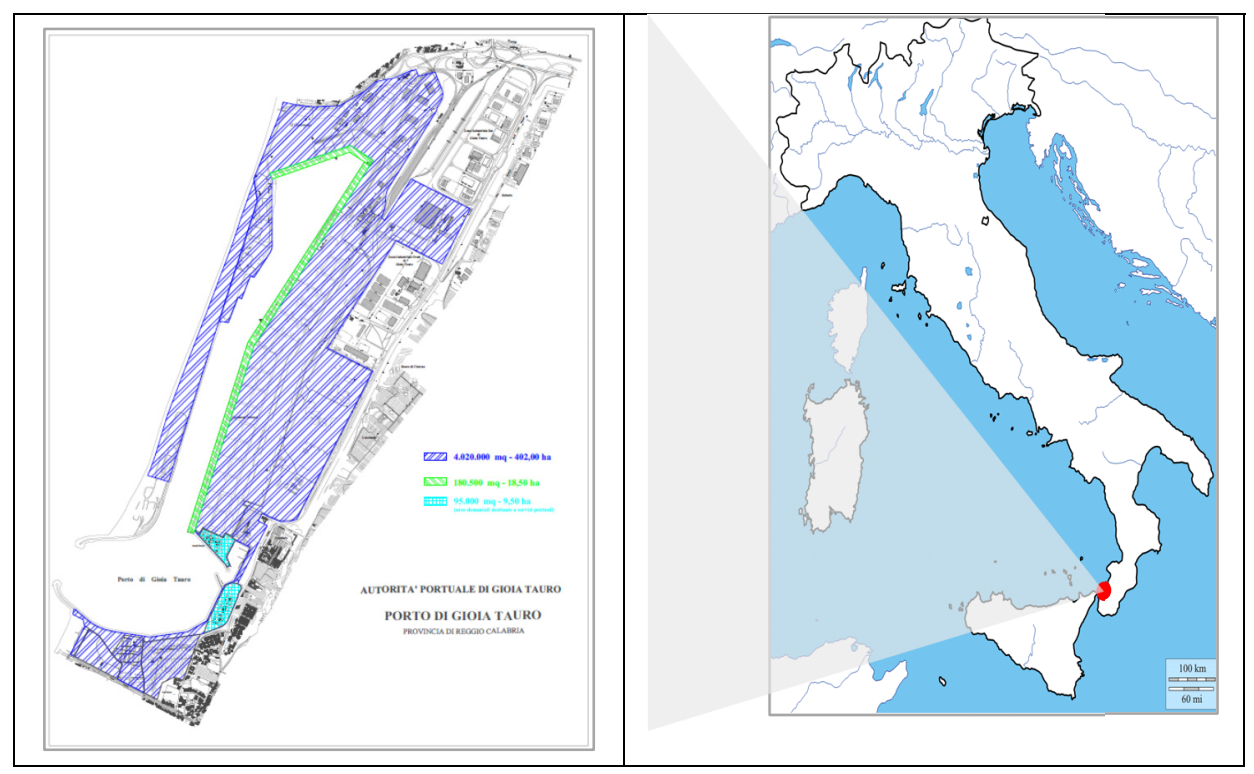

Figure 1: Port of Gioia Tauro [13].

Two terminal operators currently operate in the port:

- $\quad$ TIL, belonging to MSC Group, which carries out the main and prevalent port activity relating to the transhipment of containers with lo-lo services;

- Automar (ex BLG Logistics), operating in the automotive logistics sector with ro-ro services.

Nevertheless, Gioia Tauro aims to add a "third-generation function" by enhancing the role of the large industrial agglomeration of about 700 hectares present in its hinterland, destined to industrial, production and service activities (see [19], [20]).

As far as concerns the mechanical sector, the logistics scenario considers the current situation with the presence of:

- a container terminal operator, which needs to execute light ship maintenance;

- an automotive logistics operator, which needs to increase the storage capacity of cars and to add more services offered to the clients inside the port;

- several mechanical local and multi-national companies settled in Calabria, with their own production and logistic processes.

Therefore, the scenario aims to achieve the following objectives:

- favour the development of connections and the strengthening of the logistic capacities of the international groups settled in the port of Gioia Tauro;

- enhance the port hinterland to attract businesses, operators, local and international transport and logistics companies, which carry out entrepreneurial, commercial or handling activities, storage of goods related to the logistical processes of mechanical and automotive. 
The scenario of mechanical logistics will be implemented through the design and, therefore, the implementation of interventions in the ALI of the port of Gioia Tauro. This scenario will be able to overcome the criticalities indicated in the previous section.

\subsection{Planned interventions}

The cluster of planned interventions is located within the industrial area of the port of Gioia Tauro, located inside the municipalities of Gioia Tauro, Rosarno and San Ferdinando (see Fig. 2).

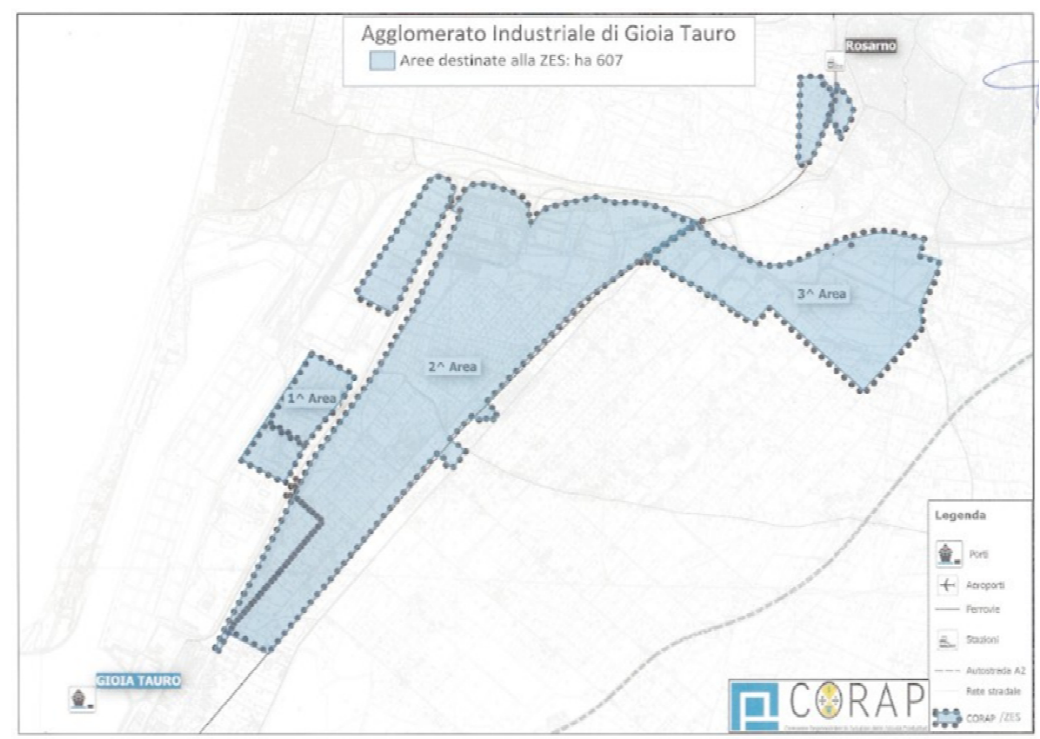

Figure 2: Industrial area of port of Gioia Tauro [13].

The decision to locate the interventions in this area is closely linked to the necessity to guarantee the connections determined by the proximity to the motorway network and the availability of areas already partially equipped with material and immaterial infrastructures.

The cluster of interventions in mechanical logistics is composed of three sub-groups (see Table 3), reported in the following paragraphs.

\subsubsection{Automotive logistics}

- Multi-floor terminal for cars: The main intervention concerns the construction of a multifloor terminal for cars aimed to supporting the existing automotive logistics. The terminal will allow to expand the storage capacity of operators who import/export cars to and from the international markets. The terminal contributes to consolidate the port of Gioia Tauro as a South European gate.

- Retraining of yards and complementary areas: The intervention aims to equip available yards and complementary areas for the storage and the execution of complementary services for the automotive logistics. 
Table 3: Planned interventions for mechanical logistics in the port of Gioia Tauro.

\begin{tabular}{l}
\hline Interventions \\
\hline Automotive logistics \\
Multi-floor terminal for cars \\
Development of yards and complementary areas \\
Special connecting roads \\
\hline Light maintenance \\
Building of the dry dock \\
Container repairing and cleaning \\
Light mechanical platform \\
General infrastructures \\
Extension of the level of service in port area: civil works \\
Extension of the level of security in port area: civil works and technological systems \\
\hline
\end{tabular}

- Special connecting roads: Other's interventions include special connecting roads between port operation area (quays) and the Development of Productive Areas area above presented. They concern the construction of special roads to support automotive logistics between the areas pertaining to the Port Authority of Gioia Tauro and the area where the multi-floor terminal for cars will be built.

\subsubsection{Light maintenance}

- Building of the dry dock: The building of the dry dock requests the resection of the western quay of the port to allocate it and the purchase of a floating dry dock. The planned interventions will modify the configuration of the west side of the port basin, without reducing the safety of the manoeuvres of the ships during the access and exit phases to and from the basin itself. The building of the dry dock was planned in two phases [27]:

○ dry dock: civil works, resection of the western quay to allocate the floating dry dock;

$\circ \quad$ dry dock: industrial plant, purchase of floating dry dock.

- Container repairing and cleaning: This intervention aims to the settlement of container repairing and cleaning centre in the hinterland of the port. The repairing activities will concern technical appraisal, damage assessment according to international standards

- Light mechanical platform: The intervention aims at the creation of a platform, which provides technical support and skills to local medium and small firms operating in the mechanical sector, presented in Section 2.1. The physical concentration of companies, currently distributed over the regional territory, is functional to the dissemination of best practices and the sharing of traditional and innovative services to support the production. The concentration makes it possible to create a production centre to support the outsourcing generated by initiatives already launched such as the dry dock.

4.2.3 General infrastructures

The interventions on general infrastructures and equipment aim to:

- increase the level of service in the port area dedicated to the automotive logistics, 
- extend the level of security of mechanical firms and logistics operators from the port and its hinterland.

Extension of the level of service: civil works for functional redevelopment, efficiency and control of street lighting, to reduce energy consumption and contain light pollution, through high-efficiency systems and the creation of control systems.

Extension of the level of security:

- civil works to increase the level of security through the construction of fences;

- technological systems by means of the realization of 24-hour surveillance systems, including the use of drones.

\section{CONCLUSIONS}

The port of Gioia Tauro is currently specialized in container transhipment operations of freight and in the automotive logistics at international level [28].

There is a high demand for mechanical logistics in Calabria, but this demand remains unsatisfied due to following critical elements:

- the lack of some transport and logistics infrastructures allowing the growth of the main existing activities in the port: transhipment and automotive logistics, and

- the presence of isolated large mechanical firms in Calabria region, linked with several small and poorly structured ones.

The planned transport interventions in the port of Gioia Tauro are identified according to the methodology defined in Section 2, in order to overcome the above criticalities and to create a specific industrial area dedicated to mechanical sector inside the port-hinterland. The proposed interventions belong to three groups, as defined inside the ALI of Gioia Tauro programme [7]: automotive logistics, light maintenance, general interventions.

The core interventions to boost the increase of the logistics related to the automotive sector is the multi-floor terminal for assembling and storing cars, in line to the development trajectories observed in the main European ports manly dedicated to automotive logistics, such as Hamburg and Zeebrugge.

The above interventions allow transhipment and automotive logistics activities present in the port to be consolidated and strengthened, and allow the establishment and consolidation of regional mechanical productions, which is one of the pillars of the regional economy.

\section{REFERENCES}

[1] UNCTAD, Port marketing and the challenge of the third generation port. Trade and Development Board Committee on Shipping ad hoc intergovernment group of Port experts, 1994.

[2] UNCTAD, Fourth-generation Port: Technical note. Ports newsletter n. 19, prepared by UNCTAD Secretariat, 1999.

[3] Russo, F. \& Musolino, G., Quantitative characteristics for port generations: The Italian case study. International Journal of Transport Development and Integration, 4, pp. 103-112, 2020. DOI: 10.2495/TDI-V4-N2-103-112.

[4] Calabria Region, Regional Transportation Plan, 2016.

[5] Russo, F. \& Chilà, G., Structural factors for a third-generation port: Actions and measures for Gioia Tauro in the regional transport plan. WIT Transactions on the Built Environment, vol. 204, 2021, accepted for publication, WIT Press, ISSN 1743-3509. 
[6] Russo, F. \& Chilà, G., Structural factors for a third-generation port: Current state, limits and weaknesses of Gioia Tauro, Italy, in the regional transport plan. WIT Transactions on the Built Environment, vol. 204, 2021, accepted for publication, WIT Press, ISSN 1743-3509.

[7] Italian Ministry of Infrastructure and Transport, Integrated Logistics Area of the Gioia Tauro pole, Development and proposal document - April 2018.

[8] Russo, F. \& Musolino, G., Estimating demand variables of maritime container transport: An aggregate procedure for the Mediterranean area. Research in Transportation Economics, 42, pp. 38-49, 2013.

[9] Leontief, W. \& Strout, A., Multi-regional input-output analysis. Structural Interdependence and Economic Development, ed. T. Barna, McMillan: London, pp. $119-150,1963$.

[10] Coppens, F., Lagneaux, F., Meersman, H., Sellekaerts, N., Van de Voorde, E., van Gastel, E., Vanelslander, T. \& Verhe, A. Economic impact of port activity: A disaggregate analysis. The case of Antwerp. Working paper document no. 110. National Bank of Belgium, 2007.

[11] Cascetta, E., Marzano, V. \& Papola, A., Multi-regional input-output models for freight demand simulation at a national level. Recent Development in Transport Modelling. Lessons for the Freight Sector, eds. M. Ben-Akiva, H. Meersman \& E. Van de Voorde, Bingley: Emerald, pp. 93-116, 2008.

[12] Russo, F. \& Musolino, G., A unifying modelling framework to simulate the Spatial Economic Transport Interaction process at urban and national scales. Journal of Transport Geography, 24, pp. 189-197, 2012.

[13] Amador, J. \& Cabral, S. Networks of value-added trade. World Economy, 40, pp. 1291-1313, 2017.

[14] Federmeccanica, L'industria metalmeccanica in cifre, 2015.

[15] European Commission, A Stronger European Industry for Growth and Economic Recovery Industrial Policy Communication Update. Communication from the Commission to the European Parliament, the Council, the European Economic and Social Committee and the Committee of the Regions, 2012.

[16] Regione Calabria, Regional Strategy for Innovation and Smart Specialization 20142020, Smart Manufacturing Sheet, 2016.

[17] ISTAT, 2001. $9^{\circ}$ Censimento industria e servizi 2011.

[18] Pirro, F., L'industria in Calabria. Un profilo di sintesi. Struttura Tecnica di MissioneMinistero delle Infrastrutture e dei Trasporti, 2017.

[19] Calabria Region, Strategic Development Plan of Special Economic Zone, 2018. portale.regione.calabria.it/website/organizzazione/dipartimento12/subsite/zes/

[20] Italian Government, Decree of the President of the Council of Ministers of 11 May 2018. www.agenziacoesione.gov.it/wp-content/uploads/2019/09/DPCM-11_05_18Istituzione-ZES-Calabria.pdf

[21] Musolino, G. \& Chilà, G., Structural factors for a third-generation port: Planning general logistics interventions in Gioia Tauro. WIT Transactions on the Built Environment, vol. 204, 2021, WIT Press, ISSN 1743-3509.

[22] Russo, F., Panuccio, P. \& Rindone, C., Structural factors for a third-generation port: Between hinterland regeneration and smart town in Gioia Tauro. WIT Transactions on the Built Environment, vol. 204, 2021, accepted for publication, WIT Press, ISSN 1743-3509. 
[23] Russo, F. \& Rindone, C., Structural factors for a third-generation port: Planning interventions for research and development in Gioia Tauro TEN-T node. WIT Transactions on the Built Environment, vol. 204, 2021, accepted for publication, WIT Press, ISSN 17.

[24] Musolino, G. \& Trecozzi, M. R., Structural factors for a third-generation port: Planning interventions for agri-food logistics in Gioia Tauro. WIT Transactions on the Built Environment, vol. 204, accepted for publication, 2021, WIT Press, ISSN 1743-3509.

[25] Russo, F. \& Musolino, G., Geographic factors affecting the presence of transhipment services in regional maritime container markets. Geographical Analysis, 45, pp. 90102, 2013.

[26] Russo, F., Musolino, G. \& Assumma, V., An integrated procedure to estimate demand flows of maritime container transport at international scale. International Journal of Shipping and Transport Logistics, 6(2), 2014.

[27] Port Authority of Gioia Tauro, Feasibility study relating to the project for the construction of a dry dock in the Port of Gioia Tauro, 2016.

[28] Cascetta, E., Nuzzolo, A., Biggiero, L., \& Russo, F. Passenger and freight demand models for the Italian transportation system. Proceedings of 7th World Conference on Transport Research, Volume 2: Modelling Transport Systems, Elsevier. 